ISSN 0103-5150

Fisioter. Mov., Curitiba, v. 29, n. 3, p. 589-596, Jul./Set. 2016

Licenciado sob uma Licença Creative Commons

DOI: http://dx.doi.org.10.1590/1980-5918.029.003.A017

(c)

\title{
Effects of resistance training in individuals with knee osteoarthritis
}

\author{
Efeitos de um treinamento de resistência muscular \\ em indivíduos com osteoartrite de joelho
}

\author{
Grazielle Cordeiro Aguiar ${ }^{[a]}$, Samira Gonçalves Rocha ${ }^{[b]}$, Gisele Aparecida da Silva Rezende ${ }^{[b]}$, Marcela Rêgo do \\ Nascimento $^{[\mathrm{b}]}$, Paula Luciana Scalzo ${ }^{[\mathrm{a}]^{*}}$ \\ [a] Universidade Federal de Minas Gerais (UFMG), Belo Horizonte, MG, Brazil \\ [b] Pontifícia Universidade Católica de Minas Gerais (PUC Minas), Betim, MG, Brazil
}

\begin{abstract}
Introduction: Osteoarthritis (OA), the most common form of arthritis, is considered the main cause of pain and disability in the elderly. Objective: To evaluate the effect of systematic muscle strength training on functional performance and quality of life in individuals with knee OA. Methods: Subjects with knee OA ( $\mathrm{n}=27$, 46 - 76 years) completed the Western Ontario and McMaster Universities Osteoarthritis Index (WOMAC), Medical Outcomes Short-Form 36-item Health Survey (SF-36), and visual analog scale (VAS) questionnaires, musculoskeletal assessments, and 10-repetition maximum and timed 10-meter walk tests both before and after training. The training consisted of an exercise resistance program and stretches for 12 weeks (three sessions of 80 each per week). Results: Twenty-two subjects completed the training. Reduced overall scores and WOMAC physical function indicated improved functional performance $(\mathrm{p}<0.001)$ as well as increased gait speed $(\mathrm{p}<0.001)$. The perception of pain decreased after training, as evidenced by the VAS, WOMAC pain domain, and SF-36 scores ( $p<0.001)$. Quality of life improvements occurred primarily in the areas of pain, functional capacity, and SF-36 physical aspects. No change in body mass index was noted ( $p=0.93)$. Conclusion: Our results indicate that the combination of resistance training for the quadriceps, gluteus, and abdominal muscles could be a viable alternative to improving functionality and quality of life in patients with knee OA. However, more studies are necessary to confirm our findings.
\end{abstract}

Keywords: Osteoarthritis. Pain. Quality of Life. Resistance Training.

\footnotetext{
*GCA: MS, e-mail: aguiargc.fisio@gmail.com

SGR: BS, e-mail: samira_rocha@yahoo.com.br

GASR: BS, e-mail: giseleresendefisio@yahoo.com.br

MRN: BS, e-mail: marcelaregofisio@yahoo.com.br

PLS: PhD, e-mail: e-mail: paula@icb.ufmg.br
}

Fisioter Mov. 2016 July/Sept;29(3):589-96 
Resumo

Introdução: A osteoartrite (OA) é a forma mais comum de artrite, considerada a principal causa de dor e incapacidade em idosos. Objetivo: Avaliar o impacto de um treinamento sistematizado de resistência muscular no desempenho funcional e na qualidade de vida em indivíduos com OA de joelho. Métodos: Voluntários com OA do joelho ( $n=27,46$ - 76 anos) foram submetidos, antes e após o período de treinamento, à aplicação dos questionários de WOMAC e SF-36 e da Escala Visual Analógica (EVA), à avaliação musculoesquelética, teste de 10 RM e teste de caminhada de dez metros. $O$ treinamento realizado consistiu em um programa de resistência muscular e alongamentos, por 12 semanas (3 sessões de 80' por semana). Resultados: 22 indivíduos concluíram o treinamento. As reduções nos escores globais e de função física do WOMAC indicam melhoria no desempenho funcional ( $p<0,001)$, assim como o aumento da velocidade da marcha $(p<0,001)$. A percepção da dor diminuiu após o treinamento, como demonstram os resultados da VAS e dos domínios dor do WOMAC e SF-36 ( $p<0,001)$. A melhoria da qualidade de vida ocorreu principalmente por modificações nos domínios de dor, capacidade funcional e aspectos físicos do SF-36. Não houve alteração no IMC $(p=0,93)$. Conclusão: Os resultados indicam que a combinação de exercícios de resistência dos músculos quadríceps, glúteos e abdômen pode ser uma estratégia viável para melhorar a funcionalidade e a qualidade de vida de pacientes com OA de joelho. No entanto, mais estudos são necessários para investigar a questão.

Palavras-chave: Osteoartrite. Dor. Qualidade de Vida. Treinamento de Resistência.

\section{Introduction}

Osteoarthritis (OA), the most common form of arthritis, is characterized by chronic joint degeneration (1). Its etiology is multifactorial, and a complex interaction of local and systemic factors lead to its development (2). OA is considered the main cause of pain and disability in the elderly and is a major cause of reduced life expectancy due to disability $(3,4)$. OA will continue to become increasingly prevalent as the global population ages $(5,6)$. The formulation of guidelines for managing the disease that aim to improve patient functional performance and quality of life is needed (7).

The knee joint is more often affected in OA, particularly in women (6). Changes in muscle function are commonly see in patients with knee $\mathrm{OA}$ and is considered as both cause and consequence of the disease. The lower limb muscles absorb load and promote dynamic stability of the knee joint, functions that are impaired in $\mathrm{OA}$ because of changes in muscle strength and flexibility $(8,9)$. Muscle weakness is considered the best predictor of disability in $\mathrm{OA}$, as altered concentric and eccentric quadriceps strength is seen in patients with $\mathrm{OA}$, and is considered to have an important role in disease onset and progression $(9,10)$. The length-tension relationship of the hip, thigh, and abdomen can also influence OA, as modification of the static and dynamic alignment of the knee and hip exposes the articular cartilage of the knee to increased focal loads $(11,12)$.

OA-related pain directly affects one's ability to execute functional activities, requiring development strategies, including the inclination of the trunk to the member in support in cases of misalignment in geno varum and can lead to weakness of the abductor muscles, which favors OA progression (12 - 14). In addition, knee or hip pain can directly contribute to the progression of sarcopenia and increased risk of falls in older women (15).

Muscular function deficiency is a modifiable state and considered a potential therapeutic target for patients with OA (10). Muscular endurance training has been explored as an intervention to prevent or delay $\mathrm{OA}$ onset $(10,16)$. Considering the lower limb as an integrated unit, the use of exercises for developing strength of the quadriceps, hamstrings, abdominals, and gluteus medius and maximus can lead to normal biomechanical restoration of the lower limb and promote OA symptom control. The objective of this study was to evaluate the effect of systematic muscle strength training on the functional performance and quality of life of patients with knee OA. 


\section{Methods}

This observational (uncontrolled) study was approved by the Research Ethics Committee of the Pontifical Catholic University of Minas Gerais (CAAE - 0129.0.213.000-09). All volunteers provided signed consent.

The sample consisted of individuals with a clinical and radiological diagnosis of knee OA waiting per attendance in the city of Betim, Minas Gerais. Initially, telephonic screening and interviews were conducted. Inclusion criteria were a diagnosis of knee OA, ability to walk without the use of assistive devices, and Mini-Mental State Examination (MMSE) scores compatible with the years of education (17). Exclusion criteria were present history of ligament injury and/or meniscal knee, history of cancer at any stage, heart disease that limited physical activity, and physical activity resulting in a fall and/or dizziness or fainting in the previous 2 months.

Both before and after the 12-week physical therapy, pain intensity assessment, physical evaluation, and walking speed measurement were performed and the questionnaires were administered.

Medical Outcomes Short-Form 36-item Health Survey (SF-36): The SF-36 is a multidimensional questionnaire consisting of 36 items divided into eight domains: physical function, role physical, bodily pain, general health, vitality, social function, role emotional, and mental health. It presents a final score of 0 - 100 points, with 0 corresponding to the worst and 100 to the best perceived quality of life (18).

Western Ontario and McMaster Universities Osteoarthritis Index (WOMAC): The WOMAC is specific to the assessment of symptoms and physical function in patients with OA of the knee and hip (19). It consists of 24 questions: five regarding pain, two for stiffness, and 17 addressing difficulties performing physical functions. It uses a Likert scale with descriptors (none, mild, moderate, strong, and very strong) corresponding to an ordinal scale of $0-4$. The higher the score, the worse the pain, stiffness, and functional limitation $(20,21)$.

Visual analog scale (VAS): The VAS assists with measuring pain intensity and is scored $0-10$, where 0 means no pain and 10 is the worst possible pain (22). Scores of 1 - 2 represent mild pain,
3 - 7 indicate moderate pain, and 8-10 correspond to severe pain $(23,24)$.

Physical evaluation: Body weight in kilograms and height in meters were measured by a scale and a measuring tape (Tanita Corporation of American, Inc., Illinois, USA). The chest, midaxillary, triceps, subscapular, abdominal, suprailiac, and thigh skinfolds were measured with a caliper (The Caliper Body, Littleton, CO, USA), following the guidelines of the American College of Sports Medicine. The measurements were used to calculate body density (BD) by the formula [BD $=1.112-0.00043499$ (sum of seven skinfolds) +0.00000055 (sum of seven skinfolds) $)_{2}$ (age)] for men and [BD = $1.097-$ 0.00046971 (sum of seven skinfolds) +0.00000056 (sum of seven skinfolds) 2 (age)] for women. From this measurement, body fat percentage was calculated using the formula $\%$ body fat $=(457 / \mathrm{BD}-$ 414.2). Circumferences of the thigh $(15 \mathrm{~cm}$ above the upper border of the patella) and abdomen $(2 \mathrm{~cm}$ above the umbilicus) were measured. Joint range of motion (ROM) was assessed passively using a universal goniometer (CARCI, São Paulo, SP BR) following the guidelines of Norkin and White on measurement positioning that evaluate hip flexion and extension, knee flexion and extension, and dorsiflexion and plantar flexion (25).

Ten-repetition maximum (10-RM): The 10-RM test was used to calculate the initial training load; after 4 - 8 weeks, it was reapplied to adjust the training load. The 10-RM test was applied to the quadriceps, hamstring, gluteus maximus, and gluteus medius muscles. For training load calculation purposes, we adopted an equivalence of $80 \%$ of the 10-RM test in relation to maximum load and later predicted the maximum load to calculate the training load within the range established at each stage $(26,27)$.

Timed 10-meter test: The timed 10-m test was used to measure walking speed. The patient was instructed to walk at a comfortable speed and avoid the interference of acceleration and deceleration. The time was recorded within the central $10 \mathrm{~m}$, while the initial and ending $2 \mathrm{~m}$ were discarded (28). The test was performed three times and the average was calculated.

Physical therapy protocol: The physical therapy protocol consisted of 12 weeks of resistance exercises and muscle stretches to promote muscle 
strength gains. The details of the exercise protocol are shown in Chart 1.

Statistical analysis: Data analysis was performed using descriptive statistics, and variables were compared using SPSS version 15.0 (SPSS Inc., Chicago, IL, USA). Values of $p<0.05$ were considered statistically significant. The Shapiro-Wilk test was used to analyze data normality, whereas Pearson or Spearman correlation coefficient of variability was used as appropriate to examine the distribution of parametric or nonparametric variables.

\section{Results}

A total of 22 individuals (18 women, 4 men) completed the training ( $81.5 \%$ adherence rate). of the five patients who did not complete training, one could not afford transportation to the clinic, three had incompatible schedules, and one had kidney stones that prevented participation.
The average participant age was $58.8 \pm 6.4$ years (range, $46-76$ years) and the mean time since the knee OA diagnosis was $5.5 \pm 3.4$ years.

Most individuals were obese, with a mean body mass index (BMI) of $30.2 \pm 5.8 \mathrm{~kg} / \mathrm{m}_{2}$ before and $29.9 \pm 5.7 \mathrm{~kg} / \mathrm{m}_{2}$ after training $(\mathrm{p}=0.93)$. The mean body fat percentage was $38.2 \% \pm 6.3 \%$ before training and $38.4 \% \pm 6.1 \%$ after training $(\mathrm{p}=0.36)$.

There was a statistically significant reduction in abdominal circumference $(\mathrm{p}=0.001)$, with values of $103.3 \pm 12.2 \mathrm{~cm}$ and $99.2 \pm 12.7 \mathrm{~cm}$ before and after training, respectively. The circumference of the right thigh was $56.1 \pm 6.3 \mathrm{~cm}$ before and 56.5 $\pm 6.9 \mathrm{~cm}$ after training $(\mathrm{p}=0.26)$, whereas that of the left thigh was $55.7 \pm 6.0 \mathrm{~cm}$ before and $56.3 \pm$ $6.7 \mathrm{~cm}$ after training $(\mathrm{p}=0.12)$.

The proposed training muscle strength improved as evidenced by the load progression.

Furthermore, the training also resulted in increased muscle flexibility (Table 1).

Table 1 - Mean and standard deviation of lower limb joint range of motion (degrees) in patients after training $(\mathrm{n}=22)$

\begin{tabular}{|c|c|c|c|c|}
\hline \multirow{2}{*}{ VARIABLES } & \multicolumn{2}{|c|}{ Right } & \multicolumn{2}{|c|}{ Left } \\
\hline & Before & After & Before & After \\
\hline Hip flexion $\left(0-120^{\circ}\right)$ & $102.55 \pm 11.13$ & $111.95^{\star} \pm 12.05$ & $102.82 \pm 11.82$ & $112.55^{\star} \pm 11.19$ \\
\hline Hip extension $\left(0-20^{\circ}\right)$ & $12.45 \pm 6.29$ & $17.09 * \pm 6.75$ & $12.41 \pm 5.89$ & $17^{\star} \pm 6.73$ \\
\hline Knee flexion $\left(0-140^{\circ}\right)$ & $111.45 \pm 15.67$ & $120.91^{\star} \pm 11.02$ & $113.45 \pm 14.35$ & $120.91^{*} \pm 10.83$ \\
\hline Knee extension $\left(-10-0^{\circ}\right)$ & $10.05 \pm 6.97$ & $5.77^{\star} \pm 6.25$ & $9.18 \pm 6.13$ & $5.36^{\star} \pm 5.64$ \\
\hline Ankle dorsiflexion $\left(0-20^{\circ}\right)$ & $16.45 \pm 5.92$ & $18.32^{\star} \pm 6.37$ & $16.27 \pm 5.50$ & $17.77 \pm 5.77$ \\
\hline Ankle plantar flexion $\left(0-50^{\circ}\right)$ & $39.27 \pm 11.10$ & $44.36^{\star} \pm 9.73$ & $39.55 \pm 11.01$ & $44.64^{\star} \pm 10.87$ \\
\hline
\end{tabular}

Note: ${ }^{\star} p>0.05,95 \%$ confidence interval was adopted.

The perception of pain decreases with training as shown by the VAS and WOMAC pain domain and the SF-36 scores (Table 2). The mean VAS score was 6.6 \pm 2.1 before and $2.5 \pm 2.2$ after training, representing an average reduction of $62.6 \%$ in pain intensity $(\mathrm{p}<0.001)$.

Our results also demonstrated a statistically significant decrease in stiffness and physical function domain WOMAC (Table 2). Furthermore, they showed an increase in usual walking speed with an average initial velocity of $0.93 \pm 0.22 \mathrm{~m} / \mathrm{s}$ and an ending velocity of $1.04 \pm 0.20 \mathrm{~m} / \mathrm{s}(\mathrm{p}<0.001)$.

The perception of quality of life mainly improved by modification of the physical parameters of the SF36 , which showed statistically significant variation in the areas of pain, functional capacity, and physical aspects (Table 2). 
Table 2 - Changes in functional performance and quality of life in patients with osteoarthritis of the knee

\begin{tabular}{l|l|l|l}
\hline \multicolumn{1}{c}{ INSTRUMENT } & Before & After & \multicolumn{1}{c}{$p$ Value } \\
\hline WomAC & $10.6 \pm 3.7$ & 5.63 .4 & $<0.001^{*}$ \\
\hline Pain subscale (0 - 20) & $4.2 \pm 2.1$ & $2.5 \pm 2.0$ & $0.014^{*}$ \\
\hline Stiffness subscale (0 - 8) & 36.313 .0 & $21.1 \pm 12.6$ & $<0.001^{*}$ \\
\hline Physical functional subscale (0 - 68) & $51.0 \pm 17.0$ & $29.2 \pm 16.5$ & $<0.001^{*}$ \\
\hline Global score (0 - 96) & \multicolumn{3}{l}{} \\
\hline SF-36 & $59.6 \pm 17.9$ & 66.117 .8 & 0.207 \\
\hline General health & $42.6 \pm 18.6$ & $60.2 \pm 22.9$ & $0.008^{*}$ \\
\hline Bodily pain & $35.7 \pm 17.6$ & $52.1 \pm 21.4$ & $0.001^{*}$ \\
\hline Physical function & $31.8 \pm 37.9$ & $60.2 \pm 37.5$ & $0.006^{*}$ \\
\hline Role physical & $63.4 \pm 19.1$ & $64.8 \pm 18.0$ & 0.728 \\
\hline Vitality & $73.9 \pm 25.3$ & $84.7 \pm 18.5$ & 0.054 \\
\hline Social function & $50.0 \pm 43.3$ & $74.2 \pm 34.0$ & 0.059 \\
\hline Role emotional & $69.1 \pm 17.0$ & $74.4 \pm 17.9$ & 0.196 \\
\hline Mental health & $53.3 \pm 13.1$ & $67.1 \pm 14.8$ & $0.001^{*}$ \\
\hline Total score & & & \\
\hline
\end{tabular}

Note: ${ }^{*} \mathrm{p}>0.05,95 \%$ confidence interval was adopted.

\section{Discussion}

The sample was composed of predominantly elderly women (81.8\%), similar to another study (6). The management of symptoms in obese subjects with knee OA may be accomplished by different treatments, such as weight reduction, use of therapeutic exercises, acupuncture, ultrasonography, laser therapy, and medications, among others (29). Concurrent treatment is recommended, especially with the first two approaches (30). This study presents a proposal for therapy resistance exercises for the quadriceps, hamstring, abdominal, and gluteal muscles as well as average maximum and related muscle stretching. Corroborating the study of Smidt et al. (31), the proposed muscle resistance training increased strength and flexibility, even without significant changes in BMI or body fat percentage.

The level of training used in this protocol is according to a meta-analysis by Rhea et al. (32). These authors showed that the ideal training range for untrained subjects is $60 \%$ of one RM to maximize strength gains. The level also corresponds to resistance training and hypertrophy, corroborating the above by Lange, Vanwanseele, and Singh (33). These authors reported that the improvement in pain symptoms in knee $\mathrm{OA}$ is more pronounced when resistance training is used. In this study, the progression change of the gluteus maximus, gluteus medius, quadriceps, and hamstring muscles was statistically significant, leading strength gain in these muscles. These findings are reinforced by improvements in physical function domain of the WOMAC in $41.9 \%$ of patients. However, there was no statistically significant increase in thigh circumference, which can be explained by the training range adopted, as it preferentially stimulates type I muscle fibers, which do not change the cross-sectional area when stimulated (34).

Exercise is considered the best approach for pain control and functional improvement (35). The pain perception results by VAS, WOMAC, and SF-36 show that resistance training for the quadriceps, hamstring, abdominal, and gluteus medius and maximus muscles led to pain reduction. This corroborates the study by Baker et al. (36), who used a similar protocol and observed improvements in strength, pain, physical function and quality of life in patients with knee OA after strength training. The results of this study 
support this finding: There was a decrease in the values obtained in all WOMAC domains, reflecting improvement in functional performance as well as increased usual walking speed.

ROM is related to disability in knee $O A$, which limits the extent of movement and external hip rotation (37). The proposed exercise program improved muscle flexibility since it increased the ROM of the hip, knee, and ankle. Study participants had a mean $27 \%$ increase in passive ROM of hip extension. Such a gain is possibly associated with increased flexibility in the hip flexors as well as an increase in strength of the hip extensors, as inferred by the statistically significant increase in strength of the gluteus maximus and hamstring muscles. However, it is possible that the dynamic ROM was also positively affected. To stoop and pick up an object on the ground, an ROM of $117^{\circ}$ of knee flexion is required; in this study, we observed an ROM of $112^{\circ}$ before and $120^{\circ}$ after training. The association between gain in ROM and reduced pain scores, stiffness, difficulty performing activities expressed by the WOMAC, and strength gain expressed by increased load indicates functional improvement with the proposed exercise protocol.

Considering that $\mathrm{OA}$ is a chronic disease, new or enhanced therapeutic measures are essential for promoting better quality of life in affected individuals. Physical function is one of the elements that contribute to an individual remaining independent and engaged in the community; therefore, it is an indicator of quality of life (38). In this study, functional performance improvement was followed by an improved perceived quality of life as evidenced by the statistically significant changes in the areas of pain perception, functional capacity, and physical aspects of the SF- 36 .

The proposed exercise program promoted muscle strength and ROM improvements as reflected by the improved performance of specific tasks requiring the same (39). The extent of adaptation to training depends, above all, on load handling, that is, the relationship between intensity and duration and frequency of exercise, as well as on adaptation, which is specific to the muscles recruited during the activity (40). The study established a dose-response relationship for the exercise; moreover, it is inexpensive, easy to apply in clinical practice, and effective in the management of knee $\mathrm{OA}$.

\section{Conclusion}

The positive results of the exercises described here support the hypothesis that physical therapy instituted in knee OA should not focus on just one muscle group; rather, it should address the major muscles associated with the pathophysiology of the disease. Other studies with greater methodological rigor (control group, double-blind design), more participants, and an analysis of muscle strength by an isokinetic dynamometer and/or electromyography could be conducted to confirm or refute our hypothesis.

\section{References}

1. Felson DT, Lawrence RC, Dieppe PA, Hirsch R, Helmick CG, Jordan JM, et al. Osteoarthritis: new insights. Part 1: the disease and its risk factors. Ann Intern Med. 2000;133:635-46.

2. Neogi T, Zhang Y. Epidemiology of Osteoarthritis. Rheum Dis Clin North Am. 2013;39(1):1-19.

3. Losina E, Walensky RP, Reichmann WM, Holt HL, Gerlovin H, Solomon DH, et al. Impact of Obesity and Knee Osteoarthritis on Morbidity and Mortality in Older Americans. Ann Intern Med. 2011;154(4):217-26.

4. Michaud CM, McKenna MT, Begg S, Tomijima N, Majmudar M, Bulzacchelli MT, et al. The burden of disease and injury in the United States 1996. Popul Health Metr. 2006;4:11.

5. Word Health Organization. Disease incidence, prevalence and disability. In: The Global Burden of Disease. 2004 [cited 2009 Apr 8]. Available from: http://tinyurl.com/jee8p4f.

6. Srikanth VK, Fryer JL, Zhai G, Winzenberg TM, Hosmer D, Jones G. A meta-analysis of sex differences prevalence, incidence and severity of osteoarthritis. Osteoarthritis Cartilage. 2005;13(9):769-81.

7. Zhang W, Moskowitz RW, Nuki G, Abramson S, Altman $\mathrm{RD}$, Arden N, et al. OARSI recommendations for the management of hip and knee osteoarthritis, Part II: OARSI evidence-based, expert consensus guidelines. Osteoarthritis Cartilage. 2008;16(2):137-62. 
8. Bennell KL, Wrigley TV, Hunt MA, Lim BW, Hinman RS. Update on the Role of Muscle in the Genesis and Management of Knee Osteoarthritis. Rheum Dis Clin North Am. 2013;39(1):145-76.

9. Hortobágyi T, Garry J, Holbert D, Devita P. Aberrations in the control of quadriceps muscle force in patients with knee osteoarthritis. Arthritis Rheum. 2004;51(4):562-9.

10. Roos EM, Herzog W, Block JA, Bennell KL. Muscle weakness, afferent sensory dysfunction and exercise in knee osteoarthritis. Nat Rev Rheumatol. 2011;7(1):57-63.

11. Kisner C, Colby LA. Exercícios Terapêuticos: Fundamentos e Técnicas. São Paulo: Manole; 1998. p. 25105, 141-80, 407-53.

12. Thorp LE, Wimmer MA, Foucher KC, Sumner DR, Shakoor N, Block JA. The biomechanical effects of focused muscle training on medial knee loads in OA of the knee: a pilot, proof of concept study. J Musculoskelet Neuronal Interact. 2010;10(2):166-73.

13. Chang A, Hayes K, Dunlop D, Song J, Hurwitz D, Cahue $\mathrm{S}$, et al. Hip abduction moment and protection against medial tibiofemoral osteoarthritis progression. Arthritis Rheum. 2005;52(11):3515-9.

14. Sled EA, Khoja L, Deluzio KJ, Oiney SJ, Culham EG. Effect of a home program of hip abductor exercises on knee joint loading, strength, function, and pain in people with knee osteoarthritis: a clinical trial. Phys Ther. 2010;90(6):895-904.

15. Scott D, Blizzard L, Fell J, Jones G. Prospective Study of Self-Reported Pain, Radiographic Osteoarthritis, Sarcopenia Progression, and Falls Risk in CommunityDwelling Older Adults. Arthritis Care Res (Hoboken). 2012;64(1):30-7.

16. Uthman OA, van der Windt DA, Jordan JL, Dziedzic KS, Healey EL, Peat GM, et al. Exercise for lower limb osteoarthritis: systematic review incorporating trial sequential analysis and network meta-analysis. BMJ. 2013;347:f5555.

17. Bertolucci PF, Brucki SD, Campacci SR, Juliano YO. The Mini-Mental State Examination in an outpatient population: influence of literacy. Arq Neuropsiquiatr. 1994;52(1):1-7.
18. Ciconelli RM, Ferraz MB, Santos W, Meinão I, Quaresma MR. Brasilian-Portuguese version of the SF36 . A reliably and valid quality of life outcome measure. Rev Bras Reumatol. 1999;39(3):143-50.

19. Lim BW, Hinman RS, Wrigley TV, Sharma L, Bennell KI. Does knee malalignment mediate the effects of quadriceps strengthening on knee adduction moment, pain, and function in medial knee osteoarthritis? A Randomized Controlled Trial. Arthritis Rheum. 2008;59(7):943-51.

20. Garratt AM, Brealey S, Gillespie WJ, DAMASK Trial Team. Patient-assessed health instruments for the knee: a structured review. Rheumatology (Oxford). 2004;43(11):1414-23.

21. Mcconnell S, Kolopack P, Davis AM. The Western Ontario and McMaster Universities Osteoarthritis Index (WOMAC): a review of its utility and measurement properties. Arthritis Rheum. 2001;45:453-61.

22. Brunelli C, Zecca E, Martini C, Campa T, Fagnoni E, Bagnasco $\mathrm{M}$, et al. Comparison of numerical and verbal rating scales to measure pain exacerbations in patients with chronic cancer pain. Health Qual Life Outcomes. 2010;8:42.

23. Briggs M, Closs JS. A descriptive study of the use of visual analogue scales and verbal rating scales for the assessment of postoperative pain in orthopedic patients. J Pain Symptom Manage. 1999;18(6):438-46.

24. Wewers ME, Lowe NK. A critical review of visual analogue scales in the measurement of clinical phenomena. Res Nurs Health. 1990;13:227-36.

25. Norkin CC, White GJ. Measuremente of joint motion: a guide to goniometry. 3rd ed. Philadelphia: Davis Company FA; 2003.

26. Losina E, Walensky RP, Kessler CL, Emrani PS, Reichmann WM, Wright EA, et al. Cost-effectiveness of total knee arthroplasty in the United States. Arch Intern Med. 2009;169(12):1113-21.

27. Ravaud P, Flipo RM, Boutron I, Roy C, Mahmoudi A, Giraueau B, at al. ARTIST (osteoarthritis intervention standardized) study of standardised consultation versus usual care for patients with osteoarthritis of the knee in primary care in France: pragmatic randomised controlled trial. BMJ. 2009;338(231):1-9. 
28. Hollman JH, Beckman BA, Brandt RA, Merriwether EN, Williams RT, Nordrum JT. Minimum detectable change in gait velocity during acute rehabilitation following hip fracture. J Geriatr Phys Ther. 2008;31(2):53-6.

29. Jordan KM, Arden NK, Doherty M, Bannwarth B, Bijlsma JW, Dieppe P, el al. EULAR Recommendations 2003: an evidence based approach to the management of knee osteoarthritis: report of a task force of the standing committee for international clinical studies including therapeutic trials (ESCISIT). Ann Rheum Dis. 2003;62:1145-55.

30. Jamtvedt G, Dahm KT, Christie A, Moe RH, Haavardsholm E, Holm I, et al. Physical therapy interventions for patients with osteoarthritis of the knee: an overview of systematic reviews. Phys Ther. 2008;88(1):123-36.

31. Smidt N, Vet HW, Bouter LM, Dekker J. Effectiveness of exercise therapy: a best-evidence summary of systematic reviews. Aust J Physiother. 2005;51(2):71-85.

32. Rhea MR, Alvar BA, Burkett LN, Ball SD. A Meta-analysis to determine the dose response for strength development. Med Sci Sports Exerc. 2003;35(3):456-64.

33. Lange AK, Vanwanseele B, Fiatarone Singh MA. Strength training for treatment of osteoarthritis of the knee: a systematic review. Arthritis Rheum. 2008;59(10):1488-94.

34. Hall SJ. Biomecânica básica. 4th ed. Rio de Janeiro: Guanabara Koogan; 2005. p. 221-259.

35. Puett DW, Griffin MR. Published trials of nonmedicinal and noninvasive therapies for hip and knee osteoarthritis. Ann Intern Med. 1994;121(2):133-40.

36. Baker KR, Nelson ME, Felson DT, Layne JE, Sarno R, Roubenoff R. The Efficacy of home based progressive strength training in older adults with knee osteoarthritis: a randomized controlled trial. J Rheumatol. 2001;28(7):1655-65.

37. Steultjens MM, Dekker J, van Baar ME, Oostendorp RB, Bijlsma JJ. Range of motion and disability in patients with osteoarthritis of the knee or hip. Rheumatology (Oxford). 2000;39:955-61. March LM, Bagga H. Epidemiology of osteoarthritis in Australia. Med J Aust. 2004;180(S5):6-10.
38. Mikesky AE, Mazzuca SA, Brandt KD, Perkins SM, Damush T, Lane KA. Effects of strength training on the incidence and progression of knee osteoarthritis. Arthritis Rheum. 2006;55(5):690-9.

Received in 09/24/2014

Recebido em 24/09/2014

Approved in 11/06/2015

Aprovado em 06/11/2015 